\title{
COMMUNICATION
}

\section{Exploring through-bond and through-space magnetic communication in 1,3,2-dithiazolyl radical complexes}

Received 00th January 20xx Accepted 00th January 20xx

DOI: $10.1039 / x 0 x \times 00000 x$
Dominique Leckie, ${ }^{a}$ Nadia Stephaniuk, ${ }^{a}$ Ana Arauzo, ${ }^{b}$ Javier Campo ${ }^{b}$ and Jeremy M. Rawson. ${ }^{a *}$
Reaction of the methyl-benzodithiazolyl radical (MBDTA) with $M(h f a c)_{2}$ complexes $(M=M n, C o, Z n)$ affords the complexes $\mathrm{M}(\mathrm{hfac})_{2}(\mathrm{MBDTA})_{2}$. Strong antiferromagnetic exchange interactions are observed between $M(I I)$ ions and the two $S=1 / 2$ radicals ( $M=M n, C o$ ), whereas weak antiferromagnetic interactions are observed between radicals when using the diamagnetic $\mathrm{Zn}(\mathrm{II})$ ion. Strong intermolecular exchange coupling is also evident in $\mathrm{Mn}(\mathrm{hfac})_{2}(\mathrm{MBDTA})_{2}$ and attributed to $\pi^{*}-\pi^{*}$ contacts between MBDTA radicals which are absent for the $\mathrm{Co}$ and $\mathrm{Zn}$ derivatives.

Significant efforts have been made to use the so-called "metalradical approach" to molecular magnetism in recent years in which exchange coupling between a metal and a paramagnetic ligand is proposed to facilitate more effective magnetic communication between metal ions than occurs via conventional diamagnetic ligands. ${ }^{1}$ In addition, recent work has focused on using spin-carrying ligands to enhance the total spin ground state of metal complexes ${ }^{1}$ and has been proposed to suppress quantum tunnelling in single molecule magnets. ${ }^{1}$ In addition, studies of metal-radical interactions can provide insight into a range of metallo-enzymes in which non-innocent redox-active ligands are proposed to play an important role in their biological function. ${ }^{2}$ To this end, the development of new families of paramagnetic ligands for metal coordination are highly desirable and a range of stable heterocyclic ligands have emerged including nitronyl nitroxide (NIT), ${ }^{3}$ verdazyl (vd), ${ }^{4}$ dithiadiazolyl (DTDA), ${ }^{5}$ benzotriazinyl (btz), ${ }^{6}$ triarylmethyl (pyBTM), ${ }^{7}$ thiatriazinyl $(\text { TTA })^{8}$ and tetrazinyl $\left(\right.$ tz $^{\bullet-}$ ) radicals $^{9}$ inter

\footnotetext{
a. Dept of Chemistry \& Biochemistry, The University of Windsor, 401 Sunset Ave, Windsor, ON, Canada, N9B 3P4.E-mail jmrawson@uwindsor.ca

b. Departamento de Física de la Materia Condensada, Facultad de Ciencias, and Instituto de Ciencia de Materiales de Aragon, CSIC-Universidad de Zaragoza, E50009 Zaragoza, Spain.

+ Footnotes relating to the title and/or authors should appear here.

Electronic Supplementary Information (ESI) available: structural information in cif format (CCDC deposition numbers 1913687 (1), 1914612 (2) and 1913688 (3), synthetic details for the formation and characterization of 1 - 3; SC-XRD, PXRD, IR and EPR studies on 1-3; computational studies on the intermolecular exchange via S $\cdots$ S and $\pi \cdots \pi$ interactions. See DOI: $10.1039 / x 0 x x 00000 x$
}

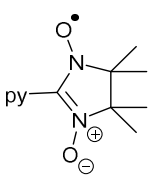

NIT<smiles>CN1C(=O)N(C)N(C)N=C1[18O]</smiles>

$\mathrm{vd}$

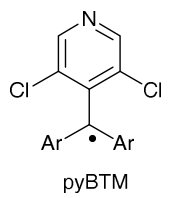<smiles>[10BH]C1=NSSN1</smiles>

DTDA<smiles>CN1SN=C(Br)N=C1Br</smiles><smiles>CC1=Nc2ccccc2N(c2ccccc2)[C@H]1Br</smiles>

btz

Scheme 1. Selected coordinating radical ligands

alia (Scheme 1). The family of 1,3,2-dithiazolyl (DTA) radicals have previously been examined as building blocks for the construction of organic 'spin transition' materials, with a number of derivatives exhibiting solid state phase transitions between $S=0$ 'pancake dimers' and two $S=1 / 2$ monomers. ${ }^{10}$ Selected salts of the benzobis(1,3,2-dithiazolyl) radical cation BBDTA $^{+\cdot}$ (Scheme 2) have shown magnetic order ${ }^{11}$ and the parent benzo-1,3,2-dithiazolyl exhibits an unusual "doublemelting" from a $\pi *-\pi *$ dimer $^{12}$ to a structurally unknown paramagnetic phase which exhibits magnetic ordering at $11 \mathrm{~K} .{ }^{13}$ The coordination chemistry of DTA radicals is less well developed. A number of N-donor DTA adducts to diamagnetic $p$-block Lewis acids have been reported ${ }^{14}$ and a single coordination complex to a paramagnetic metal ion $\mathrm{Cu}(\mathrm{hfac})_{2}$ (TTTA) (TTTA, see Scheme 2) has been described. ${ }^{15}$ In many cases radicals can be rather poor Lewis bases and incorporation of the radical into a polydentate ligand framework is desirable to assist metal coordination ${ }^{1}$ and/or a



Scheme 2. Selected 1,3,2-dithiazolyl (DTA) radicals 


\section{COMMUNICATION}

strongly Lewis acidic metal ion such as $\mathrm{M}(\mathrm{hfac})_{2}$ (hfac = hexafluoroacetylacetonate anion) have been implemented. ${ }^{16}$ In the current paper we describe the coordination chemistry of the monodentate methylbenzo- 1,3,2-dithiazolyl radical (MBDTA, Scheme 2). ${ }^{17}$ In this family of radicals substantial spin density (ca. $50 \%$ ) is located on the heterocyclic $\mathrm{N}$-donor atom ${ }^{18}$ which should favour strong metal-ligand magnetic communication. MBDTA was prepared according to the literature method ${ }^{17}$ and reacted with $\mathrm{M}(\mathrm{hfac})_{2}(\mathrm{M}=\mathrm{Mn}, \mathrm{Co}, \mathrm{Zn})$ in a 1.95:1 stoichiometry in $\mathrm{CH}_{2} \mathrm{Cl}_{2}$ at room temperature (see ESI-1). After 30 minutes the solvent was evaporated and the dark residue sublimed in vacuo $\left(10^{-1}\right.$ torr) to afford single crystals of $\mathrm{M}(\mathrm{hfac})_{2}(\mathrm{MBDTA})_{2}$ suitable for X-ray diffraction. PXRD studies on $\mathrm{Mn}(\mathrm{hfac})_{2}(\mathrm{MBDTA})_{2}$ both after removal of solvent and after sublimation clearly reveal complex formation occurs prior to sublimation (Figure S1).

The structures of the $\mathrm{Co}(\mathrm{II})$ complex $\mathrm{Co}(\mathrm{hfac})_{2}(\mathrm{MBDTA})_{2}$ (1) and $\mathrm{Zn}$ (II) complex $\mathrm{Zn}(\mathrm{hfac})_{2}(\mathrm{MBDTA})_{2}$ (2) are isomorphous, crystallizing in the triclinic space group $\mathrm{P}-1$ with half a molecule in the asymmetric unit (Figure 1). For $\mathbf{1}$ and $\mathbf{2}$ the $\mathrm{M}-\mathrm{N}$ bond lengths are 2.086(4) and 2.180(3) Å respectively. The Co-O bond lengths in 1 are $2.042(3)-2.060$ (3) $\AA$, whereas for $\mathbf{2}$ the $\mathrm{Zn}-\mathrm{O}$ bond lengths are 2.039(2) $-2.066(2) \AA$. The bond lengths to Co are consistent with high spin $\mathrm{Co}(\mathrm{II})$ expected for an $\mathrm{N}_{2} \mathrm{O}_{4}$ donor set. The MBDTA ring plane in $\mathbf{1}$ and $\mathbf{2}$ lies between the two hfac anions (Figure $\mathrm{S} 5$ ).

The structure of $\mathrm{Mn}(\mathrm{hfac})_{2}(\mathrm{MBDTA})_{2}(3)$ is shown in Figure 2 and, in contrast to $\mathbf{1}$ and $\mathbf{2}$, adopts the higher symmetry trigonal R-3 space group, with half a molecule in the asymmetric unit. The structure comprises a 6-coordinate $\mathrm{Mn}$ (II) centre with two chelate $\mathrm{hfac}^{-}$ligands in the equatorial plane and two axial MBDTA ligands. The Mn-N bond length is 2.205(4) $\AA$, whereas the $\mathrm{Mn}-\mathrm{O}$ bond lengths are 2.090(8) and 2.154(7) Å respectively. Structurally the conformation of $\mathbf{3}$ is different from $\mathbf{1}$ and $\mathbf{2}$. In all three structures the four $\mathrm{CF}_{3}$ groups can be considered to generate two clefts; one which dissects the two hfac- ligands and one which is oriented between the hfac- ligands. In $\mathbf{1}$ and $\mathbf{2}$ the plane of the MBDTA radical is located within the 'cleft' between the hfac ligands, whereas in the case of $\mathbf{3}$ the MBDTA adopts an alternative geometry which dissects both hfac ligands (Figure 3). The $\mathrm{Mn}-\mathrm{O}$ and $\mathrm{Mn}-\mathrm{N}$ bond lengths in $\mathbf{3}$ are longer than in $\mathbf{1}$ and $\mathbf{2}$ and it appears that with less steric crowding the MBDTA ring adopts an orientation which dissects

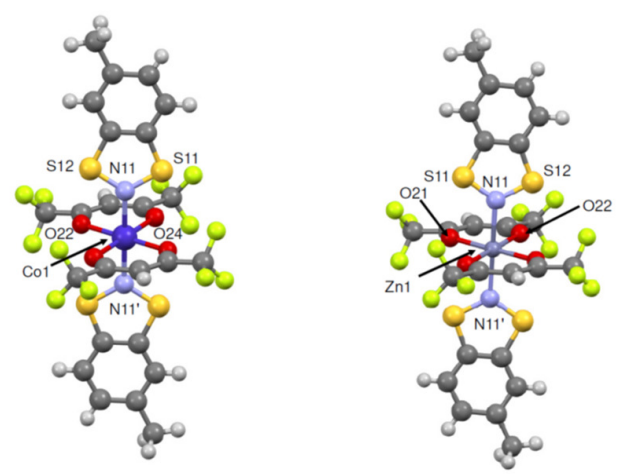

Figure 1. Crystal structure of $\mathrm{Co}(\mathrm{hfac})_{2}(\mathrm{MBDTA})_{2}(\mathbf{1})$ (left) and $\mathrm{Zn}(\mathrm{hfac})_{2}(\mathrm{MBDTA})_{2}$ (2) (right)

2 | J. Name., 2012, 00, 1-3
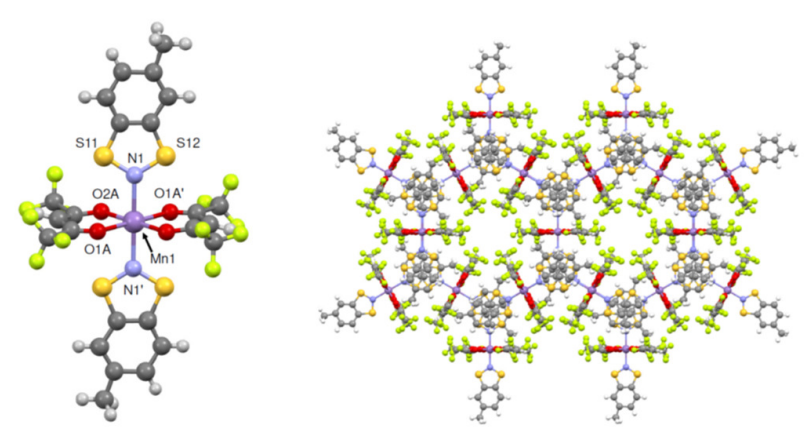

Figure 2. (left) crystal structure of $\mathrm{Mn}(\mathrm{hfac})_{2}(\mathrm{MBDTA})_{2}$ (1); (right) packing of 1 viewed down the crystallographic c-axis highlighting the hexagonal packing motif.
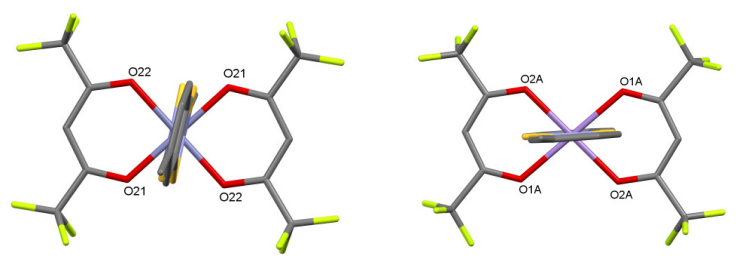

Figure 3. (left) crystal structure of (left) $\mathrm{Co}(\mathrm{hfac})_{2}(\mathrm{MBDTA})_{2} \quad$ (2) and (right) $\mathrm{Mn}(\mathrm{hfac})_{2}(\mathrm{MBDTA})_{2}(3)$ (right), highlighting the orientation of the MBDTA radical
with respect to the $\mathrm{M}(\mathrm{hfac})_{2}$ plane.

the hfac- ligands, whereas the compressed M-N and M-O bond lengths in $\mathbf{1}$ and $\mathbf{2}$ appear to favour the cleft in which the MBDTA is located between hfac- ligands. PXRD studies on 1, $\mathbf{2}$ and $\mathbf{3}$ (see Figure S2) reveal no evidence for either species adopting the alternative packing motif. The packing of $\mathbf{3}$ generates a hexagonal packing motif (Figure 2) with channels of ca. $7.4 \AA$ diameter with a hydrophobic interior made up of $\mathrm{CF}_{3}$ groups. Taking into account the van der Waals radius of $F(1.47 \AA)$, these channels are very narrow and there was no evidence from the crystal structure for inclusion of gas or solvent molecules within the pores.

Variable temperature magnetic measurements on 1 reveal a rapid decrease in $\chi \mathrm{T}$ from $2.36 \mathrm{emu} \cdot \mathrm{K} \cdot \mathrm{mol}^{-1}$ at room temperature down to $0.70 \mathrm{emu} \cdot \mathrm{K} \cdot \mathrm{mol}^{-1}$ around $70 \mathrm{~K}$ where $\chi \top$ forms a plateau (Figure 4). The value of $\chi^{\top}$ decreases again below $10 \mathrm{~K}$ to a value of $0.27 \mathrm{emu} \cdot \mathrm{K} \cdot \mathrm{mol}^{-1}$ at $2 \mathrm{~K}$. The general decrease in the high temperature regime is consistent with strong antiferromagnetic coupling between the two $S=1 / 2$ radicals and the octahedral $\mathrm{Co}$ (II) ion which has a $4 \mathrm{~T}$ term, leading to an $S_{T}=1 / 2$ spin ground state. In the low temperature regime $(T<50 \mathrm{~K})$ the data follow Curie-Weiss behaviour with $\mathrm{C}$ $=0.707 \mathrm{emu} \cdot \mathrm{K} \cdot \mathrm{mol}^{-1}$ (consistent with $\mathrm{S}_{\mathrm{T}}=1 / 2$ and $\mathrm{g}=2.74$ ) and $\mathrm{a}$ Weiss constant $\theta=-2.9 \mathrm{~K}$. The large $\mathrm{g}$ value for complex 1 originates from the presence of unquenched orbital angular momentum derived from the $\mathrm{Co}$ (II) ion. Modelling the temperature dependence of $\mathbf{1}$ in the high temperature region is complicated by the significant single ion anisotropy associated with the Co(II) ion as well as substantial exchange coupling. Nevertheless, the decrease in $\chi T$ and subsequent plateau observed for 1 in the high temperature region is comparable with that reported by Murray and co-workers for an octahedral Co(II) complex bearing two $S=1 / 2$ radicals. ${ }^{19}$ In the low temperature region, the $S_{T}=1 / 2$ ground state can exhibit no zero 


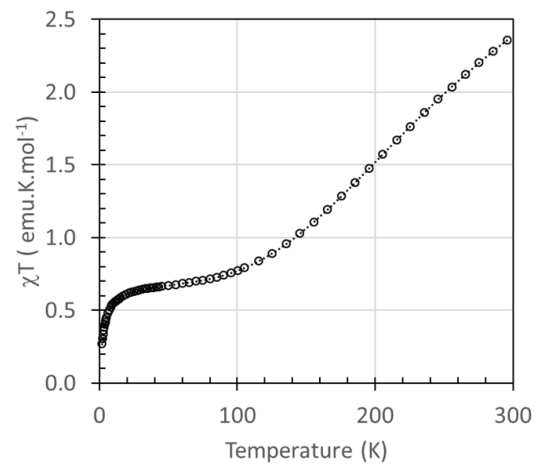

Figure 4. Temperature dependence of $\chi T$ for $\mathbf{1}$. The dotted line is a guide for the eye

field splitting and the Weiss constant $(-2.9 \mathrm{~K})$ reflects weak intermolecular antiferromagnetic interactions. In order to probe the nature of radical-..radical exchange within these complexes, we examined the magnetism of $\mathbf{2}$ in which the $d^{10}$ $\mathrm{Zn}$ (II) ion is diamagnetic. Complex $\mathbf{2}$ obeys Curie-Weiss behaviour down to $30 \mathrm{~K}$ with $C=0.754 \mathrm{emu} \cdot \mathrm{K} \cdot \mathrm{mol}^{-1}$ and $\theta=-19$ $\mathrm{K}$, consistent with antiferromagnetic exchange between $\mathrm{S}=1 / 2$ ions $\left(C=0.750 \mathrm{emu} \cdot \mathrm{K} \cdot \mathrm{mol}^{-1}\right.$ for $\left.\mathrm{g}=2.0\right)$. A plot of $\chi \mathrm{vs}$ T reveals a maximum in $\chi$ around $9.0 \mathrm{~K}$ (Figure 4 ) and a one parameter fit to the Bleaney-Bowers expression ${ }^{20}$ for two interacting $S=1 / 2$ spins $\left(\hat{\mathrm{H}}=-2 / \hat{S}_{1} \hat{S}_{2}\right)$ afforded $J / k=-4.7(1) \mathrm{K}$ (g fixed at 2.005). A small increase in $\chi$ in the low temperature region $(T<5 \mathrm{~K})$ was assigned to a small number of $S=1 / 2$ defects in the lattice.

For complex 3, a plot of $\chi \mathrm{T}$ vs $\mathrm{T}$ (Figure 5) reveals a room temperature moment of $3.16 \mathrm{emu} \cdot \mathrm{K} \cdot \mathrm{mol}^{-1}$, considerably lower than that expected for two non-interacting $S=1 / 2$ and one $S=5 / 2$ spins $\left(5.125 \mathrm{emu} \cdot \mathrm{K} \cdot \mathrm{mol}^{-1}\right)$. Strong intramolecular antiferromagnetic exchange interactions between $\mathrm{S}=5 / 2 \mathrm{Mn}$ (II) and two $S=1 / 2$ radicals would be expected to give rise to a plateau for an $\mathrm{S}_{\mathrm{T}}=3 / 2$ ground state around $C=1.875$ emu $\cdot \mathrm{K} \cdot \mathrm{mol}^{-1}(\mathrm{~g}=2.0)$ but $\chi \mathrm{T}$ decreases steadily upon cooling to $0.114 \mathrm{emu} \cdot \mathrm{K} \cdot \mathrm{mol}^{-1}$ at $2 \mathrm{~K}$. In the absence of significant single ion anisotropy, the unexpected and continued decrease in $\chi \top$ reflects the presence of additional, strong, intermolecular antiferromagnetic interactions. An initial fit of the magnetic

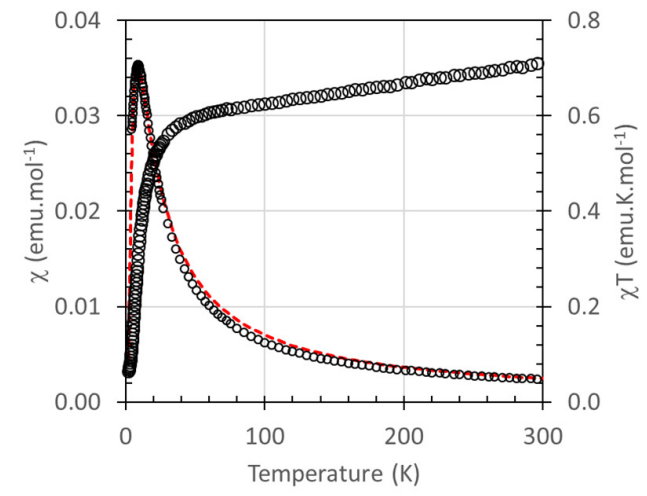

Figure 5. Temperature dependence of $\chi$ and $\chi \mathrm{T}$ for $\mathbf{2}$ with the dotted red line reflecting the fit to the maximum in $\chi$ vs T Bleaney-Bowers expression for tw interacting $S=1 / 2$ species $\left[\mathrm{g}=2.007\right.$ (fixed), $\left.\mathrm{J}=-4.7(1) \mathrm{cm}^{-1}\right]$.



Figure 6. (top) Temperature dependence of $\chi^{-1}$ for 3 with the dotted line reflecting the fit to Curie-Weiss behaviour in the high temperature region; (bottom) temperature dependence of $\chi \mathrm{T}$ for 3 with the dotted line reflecting the best two-
parameter fit to the data (see text).

data using the simple isotropic exchange Hamiltonian $\hat{\mathrm{H}}=$ $2 J\left[\hat{S}_{1} \hat{S}_{2}+\hat{S}_{1} \hat{S}_{3}\right]$ (using fixed g values for $\mathrm{Mn}(\mathrm{II})$ and DTA radicals of 1.98 and 2.006, typical for these systems) proved inadequate, predicting a plateau around $\chi \mathrm{T}=1.875 \mathrm{emu} \cdot \mathrm{K} \cdot \mathrm{mol}^{-1}$ ) consistent with an $\mathrm{S}_{\mathrm{T}}=3 / 2$ ground state. Including an additional exchange term for intramolecular radical $\cdots$ radical interactions did not improve the fit since this term is (a) likely small based on the weak nature of radical...radical exchange in $\mathbf{2}$ and (b) only enhances or suppresses the rate at which full population of the $\mathrm{S}_{\mathrm{T}}=3 / 2$ state is achieved and does not reflect the observed decrease in $\chi \mathrm{T}$ below that expected for an $\mathrm{S}_{\mathrm{T}}=3 / 2$ ground state. In the absence of significant spin anisotropy, the decrease in $\chi T$ suggested the presence of substantial intermolecular exchange. The inclusion of an additional mean field term (zJ') within $\mathrm{PHI}^{21}$ provided a very good fit to the data across the entire temperature range with $J / k=-25.3(6) \mathrm{K}$ and $z J^{\prime} / \mathrm{k}=-9.1(1) \mathrm{K}$. However, the similar magnitudes of the intra- and intermolecular exchange coupling suggest that consideration of the magnetism of $\mathbf{3}$ as a simple isolated three-spin model is inappropriate. In the limit where $J$ ' > $>J$ then antiferromagnetic coupling between radicals would quench the ligand paramagnetism leading to weakly exchange coupled $S=5 / 2$ spins in the low temperature regime which is not reflected in the observed $\chi T$ data confirming the comparable nature of intra- and inter-molecular exchange.

The weak nature of the intermolecular interactions in both 1 and $\mathbf{2}$ are in stark contrast to $\mathbf{3}$ and likely arises from the different packing in isomorphous 1 and 2 (triclinic P-1) in relation to $\mathbf{3}$ (trigonal R-3). Previous work by Preuss has shown intermolecular exchange coupling between clusters via $\mathrm{S} \cdots \mathrm{O}$ contacts between DTDA radicals (where the $S$ atom bears substantial spin density) and hfac- ligands (which bear a little spin density) become important at low temperature. ${ }^{22}$ In the current series of complexes, both $\mathbf{1}$ and $\mathbf{2}$ exhibit close 'edge-toedge' S $\cdots$ S contacts (3.558(1) $\AA$ for 2 ) which are close to the BDTA molecular plane (Figure S6), leading to rather poor orbital overlap and may be expected to lead to modest exchange coupling. Conversely in $\mathbf{3}$, the intermolecular $\mathrm{S} \cdots \mathrm{S}$ contacts comprise an out-of-plane $\pi-\pi$ type contact at 3.611(4) $\AA$ (Figure S6), reflected in a much larger intermolecular exchange coupling interaction associated with efficient SOMO-SOMO 
interactions. Computational studies on these intermolecular exchange couplings (ESI-6) confirm this perspective with nearzero computed exchange coupling $\left(\mathrm{J}_{\text {inter }}=-1 \mathrm{~cm}^{-1}\right)$ for the inplane contacts present in $\mathbf{1}$ and $\mathbf{2}$, but strong antiferromagnetic coupling associated with the $\pi \cdots \pi$ contact $\left(J_{\text {inter }}=-360 \mathrm{~cm}^{-1}\right)$ in 3.

In summary, we have shown that MBDTA acts as a monodentate donor to Lewis acidic $\mathrm{M}(\mathrm{hfac})_{2}$ complexes, providing efficient magnetic exchange between $\pi$-based radicals and metal $d$-based electrons. The manifestation of substantial intermolecular exchange coupling in $\mathbf{3}$ augers well for the construction of future materials in which the propagation of efficient, through-space magnetic exchange interactions may lead to bulk magnetic order.

\section{Conflicts of interest}

There are no conflicts to declare.

\section{Notes and references}

¥ J.M.R. would like to thank NSERC for financial support. A.A. and J.C. acknowledge support from grant MAT2015-68200-C2-2-P from the Ministerio de Economía y Competividad of Spain and the European Regional Development Fund. Additional support from Diputacioń General de Aragoń (DGA-M4) is also acknowledged.

ORC-ID A. Arauzo 0000-0002-5999-341X; J.M. Rawson 00000003-0480-5386; N. Stephaniuk 0000-0002-0749-5355; D. Leckie 0000-0002-5348-6046; J. Campo 0000-0002-3600-1721

1 (a) A. Caneschi, D. Gatteschi, R. Sessoli and P. Rey, Accts. Chem. Res., 1989, 22, 392 - 398; (b) S. Demir, I-R. Jeon, J. R. Long and T. D. Harris, Coord. Chem. Rev., 2015, 289 - 290, $149-176$.

2 W. Kaim and B. Schwederski, Coord. Chem. Rev., 2010, 254, $1580-1588$

3 (a) X. Meng, W. Shi and P. Cheng, Coord. Chem. Rev., 2019 378, 134 - 150; (b) J. Sun, Z. Sun, L. Li and J.-P. Sutter, Inorg Chem., 2018, 57, 7507 - 7511; (c) H. Li, J. Sun, M. Yang, Z. Sun, J. Tang, Y. Ma, L. Li, Inorg. Chem. 2018, 57, 9757 - 9765; (d) J. Wang, J.-N. Li, S.-L. Zhang, X.-H. Zhao, D. Shao and X.-Y. Wang, Chem. Commun., 2016, 52, 5033 - 5036.

4 (a) B. D. Koivisto and R. G. Hicks, Coord. Chem. Rev., 2005, 249, 2612 - 2630; (b) C. A. Sanz, Z. R. McKay, S. W. MacLean, B. O. Patrick and R. G. Hicks, Dalton Trans., 2017, 46, 12636 12644; (c) G. Novitchi, S. Shova, Y. Lan, W. Wernsdorfer and C. Train, Inorg. Chem., 2016, 55, 12122 - 12125; (d) A. B. Solea, T. Wohlhauser, P. Abbasi, Y. Mongbanziama, A. Crochet, K. M. Fromm, G. Novitchi, C. Train, M. Pilkington, O. Mamula, Dalton Trans. 2018, 47, 4785 - 4789.

5 (a) K. E. Preuss, Coord. Chem. Rev., 2015, 289-290, 49-61; (b) D. A. Haynes, L. J. van Laeren and O. Q. Munro, J. Amer. Chem. Soc. 2017, 139, 14620 - 14637; (c) E. M. Fatila, R. Clérac, M. Rouzières, D. V. Soldatov, M. Jennings and K. E. Preuss, J. Amer. Chem. Soc., 2013, 135, 13298-13301; (d) C. A. Michalowicz, M. B. Mills, E. Song, D. V. Soldatov, P. D. Boyle, M. Rouzières, R. Clérac and K. E. Preuss, Dalton Trans., 2019, 48, $4514-4519$.

6 (a) I. S. Morgan, A. Mansikkamäki, G. A. Zissimou, P. A. Koutentis, M. Rouzières, R. Clérac and H. M. Tuononen, Chem. - Eur. J., 2015, 21, 15843 - 15853; (b) I. S. Morgan, A.
Mansikkamäki, M. Rouzières, R. Clérac and H. M. Tuononen, Dalton Trans., 2017, 46, 12790 - 12793; (c) I. S. Morgan, A. Peuronen, M. M. Hänninen, R. W. Reed, R. Clérac and H. M. Tuononen, Inorg. Chem., 2013, 53, 33- 35.

7 (a) A. Abdurahman, Q. Peng, O. Ablikim, X. Ai and F. Li, Materials Horizons 2019, DOI: 10.1039/C9MH00077A. (b) Y. Hattori, S. Kimura, T. Kusamoto, H. Maeda, H. Nishihara, Chem. Commun., 2018, 54, 615-618; (c) Y. Hattori, T. Kusamoto, T. Sato and H. Nishihara, Chem. Commun., 2016, 52, 13393 - 13396 .

8 K. L. Harriman, I. A. Kühne, A. A. Leitch, I. Korobkov, R. Clérac, M. Murugesu and J. L. Brusso, Inorg. Chem., 2016, 55 , 5375 - 5383; (b) K. L. Harriman, A. A. Leitch, S. A. Stoian, F. Habib, J. L. Kneebone, S. I. Gorelsky, I. Korobkov, S. Desgreniers, M. L. Neidig and S. Hill, Dalton Trans., 2015, 44, $10516-10523$

9 (a) T. J. Woods, H. D. Stout, B. S. Dolinar, K. R. Vignesh, M. F. Ballesteros-Rivas, C. Achim and K. R. Dunbar, Inorg. Chem., 2017, 56, 12094 - 12097; (b) M. A. Lemes, H. N. Stein, B. Gabidullin, K. Robeyns, R. Clérac and M. Murugesu, Chem.Eur. J., 2018, 24, $4259-4263$.

10 J.M. Rawson and J.J. Hayward, "Reversible spin pairing in crystalline organic radicals" in Spin Crossover Materials: Properties and Applications (M.A. Halcrow Ed), J. Wiley \& Sons (2013).

11 (a) W. Fujita, K. Awaga, M. Takahashi, M. Takeda and T. Yamazaki, Chem. Phys. Lett., 2002, 362, 97-102; (b) W. Fujita and K. Awaga, Chem. Phys. Lett., 2002, 357, 385-388.

12 E.G. Awere, N. Burford, R.C. Haddon, S. Parsons, J. Passmore, J.V. Waszczak and P.S. White, Inorg. Chem., 1990, 29, 4821 4830.

13 W. Fujita, K. Awaga, Y. Nakazawa, K. Saito and M. Sorai, Chem. Phys. Lett., 2002, 352, $348-352$.

14 (a) W.Fujita, K.Kikuchi, K.Awaga, Angew. Chem. Int. Ed. 2008, 47, 9480 - 9483; (b) W.Fujita, K.Awaga, R.Kondo, S.Kagoshima, J. Amer. Chem. Soc., 2006, 128, 6016-6017.

15 W. Fujita and K. Awaga, J. Amer. Chem. Soc., 2001, 123, 3601 $-3602$.

16 C. M. Lieberman, A. S. Filatov, Z. Wei, A. Y. Rogachev, A. M. Abakumov and E. V. Dikarev, Chem. Sci., 2015, 6, 2835 2842.

17 (a) G. Wolmershäuser, M. Schnauber and T. Wilhelm, Chem. Commun., 1984, 573 - 574; (b) G.D. McManus, J.M. Rawson, N. Feeder, F. Palacio and P. Oliete, J. Mater. Chem., 2000, 10, $2001-2003$

18 (a) A. Alberola, R. D. Farley, S. M. Humphrey, G. D. McManus, D. M. Murphy and J. M. Rawson, Dalton Trans., 2005, 3838 - 3845; (b) G. D. McManus, J. M. Rawson, N. Feeder, E. J. L. McInnes,J. J. Novoa, R. Burriel, F. Palacio and P. Oliete, J. Mater. Chem., 2001, 11, 1992.

19 I. A. Gass, S. Tewary, G. Rajaraman, M. Asadi, D. W. Lupton, B. Moubaraki, G. Chastanet, J.-F. Létard and K. S. Murray, Inorg. Chem. 2014, 53, 5055 - 5066.

20 Magnetochemistry, R.L. Carlin, Springer-Verlag (1986).

21 N. F. Chilton, R. P. Anderson, L. D. Turner, A. Soncini and K. S. Murray, J. Comput. Chem., 2013, 34, 1164-1175.

22 E. M. Fatila, R. Clérac, M. Jennings and K. E. Preuss, Chem. Commun., 2013, 49, $9431-9433$. 